\title{
Vertical Governance between Airlines and Airports - A Transaction Cost Analysis
}

\author{
JOHANNES FUHR * \\ Berlin University of Technology
}

THORSTEN BECKERS

Berlin University of Technology

\begin{abstract}
With airport privatization and infrastructure expansion projects taking place in the liberalized European air transport market, airport and airline companies are critically reevaluating their vertical governance structures. This paper analyzes the comparative efficiency of vertical governance structures in the airport-airline supply relationship. Using transaction cost economics as the lens of analysis, we develop propositions and present supporting qualitative case studies. Our propositions state that hub airlines and hub airports seek specialized governance structures, while value-based carriers and base airports enter into long-term contracts supported by complementary safeguards. These privately crafted governance modes complement or even replace external regulation.
\end{abstract}

\section{Introduction}

European liberalization of air transport has resulted in intense competition among established airlines and new airline business models. In this competitive environment, airlines are reevaluating their firm boundaries in the quest for further efficiency gains. This is particularly important for supply relations with air traffic control providers and airports - suppliers facing either privatization or strong pressure to invest in infrastructure expansion to meet rising demand.

In both settings, (i) the equity sale of airports to private investors and (ii) the expansion of infrastructure capacity, airlines and infrastructure companies ${ }^{1}$ are forced to re-consider their vertical governance structures. ${ }^{2}$ Research on airports has traditionally focused on the welfare benefits of private ownership and regulatory aspects. In this paper, a different

* Contact author: Workgroup for Infrastructure Policy, Berlin University of Technology, Straße des 17. Juni 135, 10623 Berlin, Germany. E-mail: jf@wip.tu-berlin.de Johannes Fuhr gratefully acknowledges financial support from the Erich Becker Trust, Fraport AG. We appreciate the helpful comments of our colleagues at the Workgroup for Infrastructure Policy. We are grateful to all the industry experts interviewed for their valuable insights. Any remaining errors are our own.

${ }^{1}$ The terms "infrastructure company" and "airport" are used synonymously in the following.

${ }^{2}$ Governance structure is defined as "an institutional matrix in which integrity of the transaction is decided" (Williamson 1996, p.378). 
perspective is taken. Each of the two settings outlined is analyzed as a "boundary of the firm problem" in the interfirm supply relationship between airlines and airports.

Transaction cost economics (TCE) is applied to formulate propositions on how airports and airlines establish vertical coordination. The theory hypothesizes that the two partners will seek transaction-cost-minimizing governance structures, as these bring them closest to joint profit maximization (Ghosh and John 1999 and Williamson 1985). Transaction cost theory offers a particularly well-suited lens of analysis given its applicability to the central question of vertical integration and the strong empirical support for its hypotheses on economic organization. ${ }^{3}$

In the current paper, however, we consider its application to the supply relationship between airlines and airports as distinct from the usual empirical setting. Transactions between airlines and airports do not take place in an unregulated environment but are almost always governed (at least in part) by public owners and/or administered by government regulators. While competition is often assumed to sort out inefficient from efficient governance structures, its selection function in this context is limited due to the institutional constraints and recent nature of liberalization. As a consequence, we approach our research question by developing an informal explanatory framework and explorative case studies. We start by deriving research propositions, and then discuss them in the light of several case studies.

As the starting point for our proposals, we argue that governance structures in the supply relationships hub airline and hub airport and value-base carrier and base airport are undergoing vertical re-alignment. We propose that hub-and-spoke carriers (HSC) seek strong hybrid governance structures, which display most characteristics of hierarchical governance. HSC evaluate the hold-up threat considering the safeguarding properties of the outside government regulator. Thus, if the regulator has a poor reputation and regulatory institutions are weak, HSC incentives to build private bilateral governance structures are strengthened. Hub airports, on the other hand, need a credible commitment from hub airlines prior to investing in specific hub infrastructure.

Furthermore, we propose that weak hybrid governance structures are sought in the supply relationship between Value-Based Carriers (VBA) and base airports. While VBAs attempt to safeguard their sunk investment in regional and route-specific brand capital, base airports want to protect their investment in dedicated terminal capacity for their base carriers. We propose that these parties seek long-term contracts. Provided the base airport invests in new terminal capacity, complementary safeguards in the form of financial hostages or investment hostages are needed.

The paper proceeds as follows. In Section 2, we identify the unit of analysis - the transaction - and analyze the antecedents of frequency, asset specificity, and uncertainty in airport-airline supply relations. In Section 3, we develop propositions on vertical governance in three research scenarios: (i) privatization of a hub airport, (ii) terminal expansion at a hub airport, and (iii) terminal expansion at a base airport. We present explorative case studies to corroborate and challenge the propositions. Section 4 concludes with a discussion of results and future fields of research.

\footnotetext{
${ }^{3}$ See Boerner and Macher (2002), Klein (2005), and Rindfleisch and Heide (1997) for an overview on the extensive empirical literature.
} 


\section{Transactions between airlines and airports}

\subsection{Transaction cost economics as the lens of analysis}

The question of vertical integration and the design of interfirm supply relationships has been discussed extensively in the literature on the theory of the firm. In his recent summary of the literature on vertical integration, Joskow states that "there is not and will never be one unified theory of vertical integration" (Joskow, 2005, p.320). The different theories can be classified into market power explanations and efficiency-based explanations ${ }^{4}$. TCE belongs to the latter.

In the specific research context of airline/airport interfirm supply relationships, there has been discussion of the antitrust implications for airport lease agreements (Anonymous, 1990), market power arguments (Dresner, et al. 2002, Serebrisky, 2003), and strategic alliances (Albers, et al., 2005). In our view, transaction cost theory offers a promising lens of analysis; with it, we hope to develop the first efficiency-based explanation for the realignment of airport/airline supply relationships from a comparative economics organization perspective. One of the theory's main strengths is its operationalized framework. Furthermore, it has been validated by a large number of empirical studies. The TCE hypothesis on economic organization incorporates inefficiency in both the ex-ante investment decision, and at the ex-post level, in the contract execution phase. ${ }^{5}$

\subsection{The transaction as the unit of analysis}

Transaction cost economics owes its predictive power to the discriminating alignment hypothesis, which states that "transactions, which differ in their attributes, are aligned with governance structures, which differ in their cost and competencies, in a discriminating (mainly transaction-cost-economizing) way” (Williamson, 1991, p.277). Direct transaction costs include the cost of developing and maintaining an exchange relation, monitoring exchange behavior, and guarding against opportunism in exchange. Indirect transaction costs, on the other hand, encompass the opportunity cost of inferior performance of suboptimal governance structures, as well as the cost of maladaptation when critical information is revealed ex-post.

To start with, we need a clear definition of the transaction, which will constitute our unit of analysis. We can identify the following major transactions and associated cost positions at the airline-airport interface ${ }^{6}$ :

\footnotetext{
${ }^{4}$ The most important literature based on the market power argument deals with strategic behavior aiming at raising rival's cost in the short run or at foreclosing vertical markets in the long run (Aghion and Bolton, 1987 and Ordover et al., 1990). Traditional efficiency-based theories use production cost explanations (Panzar, 1989) or frame vertical integration as a special solution to the double mark-up problem in successive monopolies (Tirole, 1988). The dominant theories in New Institutional Economics encompass the more formal property rights approach to vertical integration (Grossmann and Hart, 1986 and Hart and Moore, 1990) and transaction cost theory (Klein et al., 1978 and Williamson, 1971, 1985). In the strategic management literature, the boundaries of the firm are often discussed by drawing on resource-based or capabilities-based theories (Barney, 1991; Peteraf, 1993; Teece et al., 1997; and Wernerfelt, 1984) and evolutionary arguments (Jacobides and Winter, 2005).

${ }^{5}$ The fact that airport infrastructure is a durable and long-term good will lead far-sighted decision-makers to assign particular importance to ex-post adjustments when deciding on the vertical governance structure.

${ }^{6}$ Transactions of approval and transactions of non-aviation commercial activities have been excluded as they do not directly occur between airlines and airports. Transactions of approval include all transactions between
} 
(1) Transactions of planning and construction are interactions between the infrastructure operators, construction companies, architects, and airlines in the design and the construction phase of the infrastructure.

(2) Transactions in the maintenance of infrastructure include all transactions aimed at maintaining the infrastructure at a defined level of service quality.

(3) Transactions in the development of infrastructure include all adjustments to the characteristics of the infrastructure during the period of operation, as customers and governmental bodies may demand these changes.

(4) Transactions in daily operations consist of all activities in the direct operation of the infrastructure. Examples include terminal management, allocation of gates, baggage tracing, and apron control.

While the latter three transactions occur in the operation stage, the planning and construction transactions take place in the investment stage. Through this up-front investment, the airport generates the option to use the infrastructure in the subsequent operating stage. ${ }^{7}$

Therefore, the relevant transaction for our analysis is the one that occurs every time the airport grants the airline the right to use airport infrastructure - such as runways, aprons or terminal - in the operating stage. Defining the unit of analysis as this kind of transfer of a property right to use infrastructure, we aggregate the above transactions into a single transaction called usage of infrastructure. In determining how to price the transaction usage of infrastructure during the operating stage, the airport includes both the cost of the up-front investment as well as the cost of maintaining, developing, and operating the infrastructure. Figure 1 displays this temporal logic in the supply relationship between airline and airports. Airports and airlines determine the governance structure prior to the investment and operating stage ${ }^{8}$, as the decision on the specificity of the investment is endogenous to the determination of the governance structure.

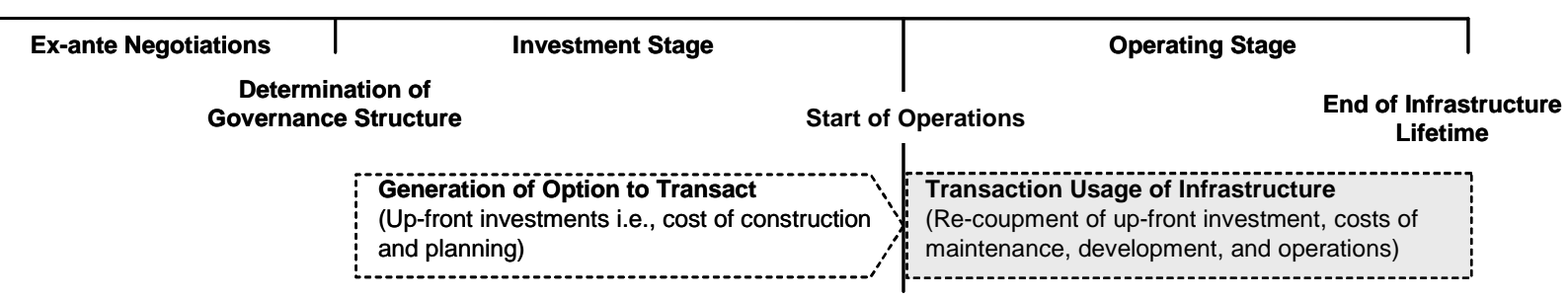

Figure 1: Transactions between airlines and airports

airports, governmental bodies, and non-government organizations during the process of ex-ante approval of the new infrastructure/airports. Transactions of commercial activities include all non-aviation activities, such as retailing, parking, etc.

${ }^{7}$ The logic described borrows from a TCE analysis on the interfirm supply relationships between railway companies and their rail track infrastructure suppliers, by Brenck et al. (2004).

${ }^{8}$ For the sake of simplicity, we do not enter into a discussion of the services (for example, terminal cleaning) being contracted out once the vertical governance structure between airline and airport has been established. 


\subsection{Transaction attributes}

Given our unit of analysis, the question is whether the attributes of the transaction usage of infrastructure are the same across all airline/airport supply relationships. In line with prior work on contractual relations in the nodes of the airline's network, our working hypothesis is that discrete differences do exist (Fuhr, 2006 and Langner, 1995). In the following, we will explore the aspects of asset specificity, uncertainty, and frequency in airline/airport supply relationships.

\subsubsection{Frequency distribution in airline networks}

Among the transaction attributes mentioned above, frequency is of secondary importance to the others. Non-specific transactions are still coordinated most efficiently in markets, even if they occur frequently. As specificity and uncertainty cause a comparative cost disadvantage for market coordination, frequency works in two opposing ways. On the one hand, high transaction frequency spreads the fixed cost of specialized governance structures over a large number of transactions. On the other, frequent interactions help build reputation, which functions as an informal safeguard (Williamson, 2005).

The transaction frequency in the airline/airport supply relation depends on the airline's network structure and the airport's role in the network.

In a hub-and-spoke network, economies of density and scope are exploited by bundling traffic at a central hub airport (Brueckner and Spiller, 1994 and Caves et al., 1984). On the supply side, the ability to employ larger aircraft types in both continental and intercontinental traffic, and higher productivity in ground operations result in significantly lower unit costs. Demand or market economies are achieved through the larger number of connections offered in a hub-and-spoke network. Integration of the hub-and-spoke carrier's flight schedule with the networks of its airline alliance partners (Shy, 2001) allows for further exploitation of these economies. The resulting transaction frequency in the nodes of a hub-and-spoke network is as follows:

(1) Hub Airports: HSC and airports display a high frequency of transactions (measured in landings), with the hub airline market share usually above $50 \%$.

(2) Secondary Airports ${ }^{9}$ : HSC and airports display a moderate to high frequency of transactions. Traffic generated at these airports contributes a substantial part of feed into the network.

(3) Other Spoke Airports. Transaction frequency is low, as these airports contribute a small portion of traffic to the network, but they are greatest in number. ${ }^{10}$

In the United States, the hub-and-spoke system is considered an outcome of deregulation (Reynolds-Feighan, 2001 and Shy, 2001). Analysis of the temporal

\footnotetext{
${ }^{9}$ The term secondary airport borrows from a classification of airports by Hirschhausen et al. (2004).

Secondary airports are situated in large catchment areas, provide a large portion of the HSC network feeder traffic, and attract point-to-point traffic.

${ }^{10}$ Applying this classification, Fuhr (2006) finds the following cumulative frequency distribution in an empirical analysis of a hub-and spoke network: the two hub airports contribute $44.1 \%$ of all aircraft take-offs (54.5\% of all departing passengers); adding the ten largest spoke airports brings the number to $75.7 \%$ (80.8\%) with the remaining 58 spoke airports in the network contributing the other $24.3 \%$ (19.2\%). All figures are derived from the analysis of a single European HSC for airports within the European Union.
} 
configurations of European hub-and-spoke networks shows that HSCs in Europe have also increasingly relied on hubbing since deregulation (Burghouwt and De Wit, 2005).

The second phenomenon resulting from deregulation has been the emergence of a competing business model. Value Based Airlines (VBA) - more commonly know as Low Cost Carriers - employ a linear network structure with short and mid-distance flights in their route portfolio. ${ }^{11}$ In these linear networks, frequency is more evenly distributed (Reynolds-Feighan, 2001). VBAs maintain supply relations with two types of airports: base airports and non-base airports. At a base airport, planes, personnel and in some cases supporting services (such as aircraft maintenance facilities) are stationed. These airports are located in attractive catchment areas, in which the VBA attempts to build a strong regional brand to generate demand for the large number of routes originating from the base airport. Similar to the relationship between hub carriers and hub airports, a single VBA dominates its base airports. Table 1 shows a selection of dominant carriers at hub or base airports, including their market shares and shares in the number of transfer passengers.

\begin{tabular}{|l|c|l|c|c|}
\hline Airport & $\begin{array}{c}\text { Business } \\
\text { Model }\end{array}$ & $\begin{array}{c}\text { Dominant } \\
\text { Carrier }\end{array}$ & $\begin{array}{c}\text { Market } \\
\text { Share }\end{array}$ & $\begin{array}{c}\text { Transfer } \\
\text { passenger }\end{array}$ \\
\hline Amsterdam (AMS) & HSC & KLM & $76 \%$ & $58 \%$ \\
\hline Frankfurt (FRA) & HSC & Lufthansa & $75 \%$ & $65 \%$ \\
\hline Paris (CDG) & HSC & Air France & $73 \%$ & $44 \%$ \\
\hline Munich (MUC) & HSC & Lufthansa & $63 \%$ & $46 \%$ \\
\hline Heathrow (LHR) & HSC & British Airways & $51 \%$ & $34 \%$ \\
\hline Hahn (HHN) & VBA & Ryanair & $93 \%$ & $\mathrm{n} / \mathrm{a}$ \\
\hline Berlin (SXF) & VBA & Easyjet & $46 \%$ & $\mathrm{n} / \mathrm{a}$ \\
\hline Cologne (CGN) & VBA & Germanwings & $31 \%$ & $\mathrm{n} / \mathrm{a}$ \\
\hline Stansted (STN) & VBA & Ryanair & $63 \%$ & $\mathrm{n} / \mathrm{a}$ \\
\hline Luton (LTN) & VBA & Easyjet & $58 \%$ & $\mathrm{n} / \mathrm{a}$ \\
\hline
\end{tabular}

Table 1: Market shares at European hub and base airports

Source: MIDT, 2004.

The transaction frequency in the supply relation between VBA and airport is as follows:

(4) Base Airports: Transaction frequency between VBA and base airport is moderate to high. A single VBA dominates its base airport and disposes over a large market share.

(5) Non-Base Airports: Transaction frequency is low, as these airports only connect to a few other airports in the linear network.

\footnotetext{
${ }^{11}$ In the literature, there is no uniform definition of a Low Cost Carrier (LCC) or Value Based Airlines (VBA). In our study, we regard the linearity of the network structure as the key criterion. However, it should be noted that the sharp distinction between the classic VBA and the HSC business model is blurring due to the introduction of hybrid business models and network structures. Nevertheless, we regard the focus on the polar models as sufficient for our analysis. The abbreviations LCC and VBA are used synonymously.

${ }^{12}$ Market shares and transfer quotas are based on the number of departing passengers. At hub airports, alliance partners of the local HSC have been included.
} 


\subsubsection{Uncertainty}

The behavioral assumption of bounded rationality in TCE relaxes the classic assumption of perfect information. In consequence, individuals are unable to assign probabilistic values to future states of contingencies. Economic agents will thus estimate the degree and consequences of environmental uncertainty based on their past experience and present expectations. Both the frequency of disturbance as well as the degree of consequentiality determine the need and the required adaptive capabilities in exchange relationships (Ménard, 2004). Market coordination is best suited to coordinate exchange when uncertainty is low and market participants adapt autonomously on the basis of information provided via the market price mechanism. As uncertainty increases, price alone becomes unable to coordinate exchange efficiently. Autonomous adaptation is increasingly replaced by coordinated adaptation in hybrids, and in the extreme, substituted with full administrative controls ${ }^{13}$ in hierarchical governance (Williamson, 1991).

As parameters of the state of nature are revealed, transaction partners face behavioral uncertainty of their counterpart as economic actors are assumed to be opportunistic. The resulting strategic behavior includes non-disclosure and disguise of relevant information in the adaptation process (Williamson, 1985). The resulting behavioral uncertainty has been conceptualized as the difficulty or cost of performance evaluation (Ghosh and John, 1999 and Rindfleisch and Heide, 1997). Performance evaluation tends to be especially difficult with complex transactions, as "more details need to be accounted for and more dimensions exist in which something can go wrong” (Masten, 1984, p.193).

As uncertainty is hard to define ${ }^{14}$, let alone to measure, we attempt to identify the extent and sources of uncertainty in the ex-ante determination of the price for the transaction usage of infrastructure in the operating stage. Farsighted airport planners will determine the pricing of the transaction based on the projected traffic growth, as well as an estimate of the investment volume and running cost during operations. If uncertainties are negligible, the partners can write a permanent long-term contract or define a price adjustment formula ex ante.

In terminal and airport expansion projects - as in most infrastructure projects - costs are sunk the moment the capacity is generated, and time horizons of 30 years or longer are common. Substantial uncertainties exist on both the demand and the supply side of the transaction. They arise due to the following uncertainties:

- $\quad$ accuracy of the demand forecast and the nature of demand

- $\quad$ investment volume in the design, planning and construction phase

- $\quad$ costs of infrastructure maintenance and operation

- costs of infrastructure development due to technological changes, customer needs, or changes in legal or governmental regulations

\footnotetext{
${ }^{13}$ Some researchers have argued that uncertainty acts as disincentive for vertical integration in high technology industries. For a discussion on the role of uncertainty on the generic governance modes market, hybrid, and hierarchy see Ménard (2004), Williamson (1991), and Rindfleisch and Heide (1997).

${ }^{14}$ See Rindfleisch and Heide (1997) for an analysis on the different definition of uncertainty in the TCE literature. See also Klein (2005) for a critique on the treatment of uncertainty in empirical studies in TCE.
} 
When environmental uncertainty is introduced to the contracting problem described, the price determined ex-ante has to be adjusted as contingent states of demand and supply condition materialize. Since writing a complete contingent contract is either not feasible or comes at prohibitive costs, airlines and infrastructure suppliers enter into ex-post renegotiations. The effects of demand changes and cost developments on an equitable price of the transaction during the operating stage are difficult for outside parties to estimate, and it is thus impossible to objectively determine the adjusted price. In an attempt to estimate an "equitable" 15 price, outside parties such as airlines or arbitrators face substantial information asymmetries. For example, airport suppliers can behave strategically, that is, not disclose full information on the true effects of the external changes. ${ }^{16}$ These information asymmetries have the most severe effect in complex transactions that take place between airlines and their hub airports and large secondary airports. Determination and allocation of costs, for example, becomes increasingly difficult as one moves from simple regional airports to larger airports with multi-product offerings.

\subsubsection{Asset specificity}

Asset specificity takes on a dominant role in TCE in explaining efficiency differentials between the generic governance modes of market, hybrid, and hierarchical governance. Exchange partners place value on a continuation of an existing exchange relationship based on their investments in relationship-specific assets. The resulting quasi-rent is defined as the excess of an asset's value over the value of its best alternative use or user (Klein et al., 1978). This excess of return keeps the asset in its current use, and can include pure rents as well (Holmstrom and Roberts, 1998). In the literature, six different conditions of asset specificity have been developed: site, physical, human capital, brand, dedicated, temporal, and contractual asset specificity (Masten et al., 1991; Pirrong, 1993; and Williamson, 1985).

Two characteristics of idiosyncratic investments are particularly noteworthy: first, mutual gains from specific investments exceed the gains of non-specific investments, and second, restricted redeployability of a relation-specific asset causes a fundamental transformation (Williamson, 1985). A fundamental transformation occurs as the build-up of specific assets turns a large number ex-ante bargaining situation for the supply of a good or a service into a small number bargaining situation ex-post. The resulting mutual dependency either occurs immediately through a joint investment or is built up continuously as partners invest in complementary assets (Ménard, 2004). We argue that these different forms of quasi-rent creation are of particular importance in our research settings. In the following, a distinction is thus needed between the airport's and the airline's perspective on the origins and extent of quasi-rents.

\footnotetext{
${ }^{15}$ Partners to exchange have an incentive to devise terms that provide for an "equitable" division of ex-post contractual surpluses, as this minimizes the probability that contracts will be re-negotiated or performance will be evaded. See Masten and Saussier (2002) for a discussion on the term "equitable” in the literature.

${ }^{16}$ The example given refers to strategic behavior of the infrastructure company. Airlines, however, might as well behave strategically. Airports rely on growth estimates provided by the airline based on its expected success of its business model. These estimates might be over-estimate or inherent business risk might not be fully disclosed.
} 
Airline Perspective. What are the antecedents of an airline's quasi-rents in the supply relation with a particular airport? We argue that they are reflected in the cost of excluding the airport from its network (this includes the opportunity cost of foregone profits as well). To put it differently, to what extent can the airport hold up the airline by raising its prices for the usage of its infrastructure before the airline will either downgrade the airport in its network hierarchy or stop servicing the airport? ${ }^{17}$

Intuitively, one would argue that quasi-rents are greatest for hub airports, less for large secondary airports with their substantial feeder traffic, and insignificant for simple spoke airports. In linear networks, on the other hand, the losses incurred for switching base airports will exceed the costs of substituting non-base airports in the network. We attempt to substantiate this intuition by exploring the nature of site-specific investments and investments in human capital and brand name capital in more detail.

Site-specificity at hub and secondary airports includes the HSC's investments in maintenance and training facilities to assure the high productivity of operations at these airports. However, a far greater source of quasi-rents is rooted in the optimization of the hub-and-spoke flight schedule. These quasi-rents originate through a mixture of human capital asset specificity in the scheduling process itself (Langner, 1995) and site specificity through grandfathered slots and bilateral traffic rights. ${ }^{18}$ Flight schedules are planned around the hub airport and are continuously optimized through a trial-and-error procedure in order to determine which (new) destinations are profitable or which combination of aircraft rotations result in the highest asset productivity. In this revolving scheduling process, slots and international traffic rights are taken into account as constraints. In consequence, the cost of switching a hub airport within a fully developed schedule will be extremely high. Secondary airports will also create quasi-rents, although to a lesser extent, as the upstream and downstream traffic is aligned with the banks of connecting flights in the hub. Again, as large secondary airports are slot-constrained, matching slot pairs are attained over time to optimize the feeding structure.

In contrast to the bilateral dependency arising from site-specific investments and the specificity of human capital assets discussed above, quasi-rents will be far lower in the supply relations of value-based carriers with their airports. In most cases, training and technical maintenance is contracted out, airports in the networks are usually not slotconstrained, and the VBA's business model is not affected by international bilateral agreements. ${ }^{19}$ Even though the trial-and-error procedure determining the optimal route portfolio of point-to-point routes originating from a base airport still applies, the resulting quasi-rents are smaller. Optimization is less complex, being restricted to a subpart of the network, is based on a single aircraft type, and is subject to fewer constraints. Human capital asset specificity and site-specific investment are in most cases negligible. To a

\footnotetext{
${ }^{17}$ Besides the extreme option of stopping to service the airport, the airline can change the hierarchical role of the airport in its network. HSCs might downgrade a former secondary airport to a simple spoke airport, while VBAs might turn a former base airport into a non-base airport.

${ }^{18}$ A slot is a time window in which the airline is entitled to use the runway of a congested airport. In Europe, slots are not allocated through markets, but are quasi-owned by airlines on a historical basis ("use it or lose it rule” or grandfather rights). Bilateral traffic agreements specify the traffic rights and the number of flights between two countries. These rights are not carrier-specific, but are tied to a specific airport or country. ${ }^{19}$ The full range of "freedoms of the air" are granted to carriers with operating certificates in the European Union since the implementation of the final liberalization package in 1997.
} 
certain degree, site-specific investments at their large base airports occur as VBAs either invest in their own maintenance facilities or enter into long-term maintenance contracts. ${ }^{20}$

However, investment in brand building in the catchment area of the base airport is considered a substantial sunk cost. The success of the VBA business model is rooted primarily in lower unit costs due to employment of one single, large aircraft type, the high productivity of resources and personnel, and the omission of complexity-driven services. In order to attain a high seat load factor, VBAs must mobilize sufficient demand through lower prices and significant advertising expenditures in the respective catchment area. The value of such mobilized demand through the establishment of local "low-cost brands" at the catchment as well as at the route level causes the VBA to value a continuing relationship with its base airport supplier.

A similar line of argument applies to the HSC and its sunk costs in brand building for transfer connections via its hub airport. Such decentralized and route-specific brand capital is built up through indirect distribution channels (via travel agencies) as well as with direct customers (Langner, 1995).

Airport Perspective. In the preceding analysis on the antecedents of quasi-rent creation in hub-and-spoke and linear networks, we argued that most specific investments are of the continuous type and are gradually built up in the establishment of the airline's network. Airports, on the other hand, are faced with a potential immediate creation of quasi-rents through an idiosyncratic "spot" investment.

In our view, dedicated asset specificity and physical asset specificity of airport infrastructure are the antecedents to bilateral dependency between airports and specific carriers. The airport determines the specificity of the investment in its decision on the capacity and functionality of infrastructure in the early part of the planning and design stage.

Assuming the airport intends to expand its terminal and/or runway capacity, it faces the option of investing in either a general-purpose asset or a specialized asset. A generalpurpose asset would provide sufficient capacity to serve local demand in the catchment area and include basic functionalities, that is, standard spoke terminal and continental runway technology.

Now assume both airport and a particular airline can mutually gain through the (further) development of a hub-and-spoke network, given that adequate hub infrastructure is provided. Specialized hub infrastructure allows for optimal transfer processes and results in a comparative competitive advantage of the HSC. The infrastructure company is now confronted with an investment in relationship-specific infrastructure.

Physical asset specificity is caused by terminal layouts specific to transfer passenger processes, investment in a high-speed and automated baggage system for dedicated logistic processes, and runways for intercontinental airplanes. Dedicated asset specificity exists as terminal and runway capacities are now designed not only to provide for local traffic, but for expected transfer traffic.

For the airport to recover its sunk investments, it must work with the HSC for a defined period of time and for an expected traffic growth path. Quasi-rents accrue due to the difference in value between the optimal and the second-best use of the hub infrastructure. Following our classification of airports, this second-best use will be that of a secondary

\footnotetext{
${ }^{20}$ The underlying logic of these investments at large base airports is an increase in aircraft productivity. The productivity gains are derived from the quick resolution of technical problems during operations and routine maintenance checks, which take place at night, when aircrafts are parked for their night stopovers.
} 
airport in the HSC network. As argued above, it is unlikely that the infrastructure company will attract an equally well-suited HSC, as other hub-and-spoke carriers are already locked into their respective hub airports.

So far our line of argument assumes that airports generally do not compete in the same catchment area or to attract new carriers. However, this assumption appears invalid particularly in the case of VBAs and their strategy of network expansion. These carriers evaluate and negotiate with various base airports across Europe prior to establishing new airports in their network. Non-base airports are unlikely to invest in new capacity, as underutilized existing capacity suffices in most cases to handle the additional volume. Potential base airports, however, are faced with infrastructure expansion at least on the terminal side when VBAs begin establishing large-scale operations. Even though VBAs demand general purpose infrastructure matching their low-cost business model (Barrett, 2004), quasi-rents are created as dedicated capacity exposes the airport to a hold-up situation. In the early development of their linear network at the base airport, VBAs are still able to exit the catchment area or withhold growth at little cost. Alternative VBAs, on the other hand, will either be locked into their base airports or able to exploit the weak bargaining position of the airports due to sunk investments.

\section{Vertical governance: Some propositions}

So far, the focus has been on the attributes of frequency, uncertainty, and asset specificity of the transaction usage of infrastructure and on the differences in the stylized airline/airport supply relationships. Following the heuristics in TCE, specialized vertical governance structures should surface in supply relations between HSCs and their hub airports and VBAs and their base airports. We have argued that in these exchange relationships, transaction frequency is substantial, environmental uncertainty is significant, and relationship-specific investments of both the continuous and the immediate type occur. Based on our transaction cost reasoning, first propositions on the vertical governance decision are developed in three supply scenarios: (i) privatization of a hub airport, (ii) terminal expansion at a hub airport, and (iii) terminal expansion at a base airport.

These propositions are supported and challenged via explorative case studies on occurrences of specialized vertical governance structures between airlines and airports. For scenario (i) privatization of a hub airport, we explore Lufthansa's ${ }^{21}$ recent minority investment in Frankfurt International Airport. The Terminal 2 joint venture between Lufthansa and Munich Airport is subject to analysis in the second scenario. Third, we attempt to shed some light into the contracting practices between VBAs and base airports in Germany.

We have several objectives in presenting these short case studies. First, we analyze the airlines' and airports' goals and incentives for creating specialized vertical governance modes. Second, we elaborate on the costs and competencies of the chosen organizational form and contrast them against a purely administered transaction by an outside regulator. Finally, we evaluate the degree to which the evidence presented corroborates our transaction cost reasoning and propositions.

\footnotetext{
${ }^{21}$ Lufthansa German Airlines (Lufthansa) is a publicly listed company, which has been fully privatized since 1997. Next to British Airways and Air France, it is Europe’s largest hub-and-spoke carrier.
} 


\subsection{Hub airport privatization}

The alignment with a transaction cost minimizing governance structure in the airline/airport supply relationship differs from the typical contractual problem addressed in the TCE empirical literature. In the majority of cases, the transaction usage of infrastructure is not privately governed in a dyadic supply relationship, but administered by a government regulator. The transaction cost (administered contract) perspective analyzes economic regulation in process terms rather than as a substitute for competitive market forces ${ }^{22}$ (Crocker and Masten, 1996).

In his seminal work on regulation as an administered contract, Goldberg (Goldberg, 1976, p.431) contrasts the perspectives as follows.

"in searching for a rationale for regulation we should look not at the shape of the long-run average cost curve, but instead at the complexities involved in devising and administering such a contract ... natural monopoly industries will be characterized ... not by their alleged decreasing average cost: but by the feature which make long-term relationships between consumers and producers desirable”

Further, Williamson (1999) argues from a comparative economic organization perspective that both public ownership ${ }^{23}$ and regulation as discrete governance modes offer safeguards against extreme conditions of bilateral dependency and information asymmetry beyond those that can be privately crafted.

However, the relationship between airline and airport differs in important aspects to the usually stylized relationship between utility companies and consumers. First, the contractual problem is situated in the intermediate goods or services market. Thus, information asymmetries are less severe and it is feasible to create specialized governance structures. On the other hand, airports can only partially be considered a natural monopoly industry as they do face competition in certain market segments (Starkie, 2002).

From an institutional point of view, airport price regulation represents a long-term contract between airports and airlines that is enforced by a third party - in our case, a government regulator. However, such trilateral governance of the transaction (Williamson, 1985 and Wolf, 2004) might be further supported by a privately crafted dyadic governance structure. $^{24}$

Why is this? From the airline's perspective, regulation represents a safeguard against opportunistic pricing behavior by the airport. The regulator evaluates the adequacy of the airport's pricing proposal for the transaction usage of infrastructure on the basis of the cost and revenue data provided. The resulting price is then applicable to all airlines transacting with the airport. For the majority of airlines serving a hub airport, regulation represents a transaction cost minimizing governance structure.

The local HSC, on the other hand, will be particularly vulnerable to hold-up by the airport, as it has accumulated large quasi-rents in the development of its hub-and-spoke schedule. As the hub airport makes the transition from public to private ownership, the local HSC will evaluate the safeguarding properties of the regulatory regime. In any case, the regulator faces a problem of information asymmetry in its evaluation of the adequacy

\footnotetext{
${ }^{22}$ From the neoclassical perspective, price regulation represents a second-best response to a condition of (uncontested) natural monopoly. Regulation is considered as an imperfect substitute for competition.

${ }^{23}$ Public ownership is not subject to further analysis. We assume that public owners, intending to (partially) privatize a hub airport, will start to behave like private investors.

${ }^{24}$ The privatization of NATS (Air Traffic Control in the UK), for example, resulted in a strong hybrid governance structure (today $42 \%$ ownership stake by an airline consortium). As prices of NATS are determined via a price cap formula, regulation and vertical integration apparently act as complements.
} 
of the airport's pricing proposal. The complexity of the pricing decision for the transaction usage of infrastructure in the hub supply relationship will further facilitate the airport's strategic behavior. Put differently, the cost of measuring current performance and estimating future performance in the determination of an equitable price may be extremely high for an outside party. The hub airport's management may not fully disclose or may even distort information on the effects of parametric changes in cost or revenue conditions. Through the acquisition of equity ownership in its hub airport, the HSC becomes an inside party, and establishes a complementary private safeguard to regulation. A regulator with a high reputation and strong institutional support for enforcing regulation will mitigate the HSC's incentive to seek equity ownership in its hub airport.

Proposition 1a: HSCs seek equity ownership in their respective hub airports to safeguard their accumulated quasi-rents by accessing private enforcement mechanisms.

Proposition 1b: Effective regulation and high reputation of the regulator will weaken the hub airline's incentives to safeguard the transaction via a privately crafted, vertically integrated governance structure in its dyadic supply relationship with its hub airport.

\section{Case study 1: Privatization of Frankfurt International Airport}

Frankfurt airport is Lufthansa's primary hub airport and the third-largest airport in Europe in terms of passengers (52.2 Mio. passengers in 2005). Lufthansa's market share is about $58 \%$, and its share of transferring passenger amounts to approximately $65 \%$. Frankfurt Airport is slot-constrained as it operates at its runway capacity limit most of the day.

When Frankfurt Airport was partially privatized in 2001, its public owners sold $29.4 \%$ of the airport's equity in an initial private offering. Prior to going public, ownership had been split between the federal government of Germany (25.9\%), the federal state of Hessen (45.2\%), and the city of Frankfurt (28.9\%). In the last quarter of 2005, the federal government sold another $11.6 \%$ of its remaining shares via a private placement to institutional investors. In this second privatization tranche, Lufthansa acquired a $4.9 \%$ share in Frankfurt International Airport and has subsequently increased its stake to $9.1 \%$. Lufthansa had several objectives in the acquisition of this minority equity stake:

- More direct influence on the airport's strategic and investment decisions via a seat on the supervisory board ${ }^{25}$

- A higher degree of operational and process quality, based on a shared understanding of each company's processes and objectives

- $\quad$ Stronger control on the airport's cost development

In its strategic assessment of the European air transport market, Lufthansa stresses that competition is increasingly taking place at a new level: between whole air transport

\footnotetext{
${ }^{25}$ According to the German law on co-determination (MitbestG), the supervisory board must be paritystaffed by representatives of shareholders and employees. Active members of the board of directors are not allowed to serve on the supervisory board ( $§ 105 \mathrm{AktG}$ ), as the supervisory board's main functions are to appoint and control the company's board of directors.
} 
systems rather than simply between airlines. This, in turn, requires a closer vertical coordination between hub carrier, hub airport, and national air traffic control. ${ }^{26}$

We have proposed that HSCs, faced with the privatization of their respective hub airports, will evaluate the safeguarding properties of the outside regulator. In comparison with sophisticated regulatory regimes, such as those in the UK, price regulation for Frankfurt Airport and its supporting regulatory institutions must be considered weak. The current cost-plus regulation is unlikely to serve as an appropriate safeguard. ${ }^{27}$ In line with proposition 1b, we argue that the conflict of interests of the federal state of Hessen in its dual role as regulator and owner, combined with the lack of well-developed regulatory institutions, has strengthened Lufthansa's incentive to seek an equity stake. As its hub-andspoke network is fully developed and site-specific investments are large, Lufthansa aims to protect its accrued quasi-rents (proposition 1a). In contrast to a purely administered contract by an outside regulator, Lufthansa gains access to inside information as well as special enforcement mechanisms through its seat on the supervisory board.

Frankfurt Airport's upcoming investment volume amounts to approximately 3.4 billion euros for additional terminal and runway capacity until the year 2015 (Schulte, 2005). Lufthansa has stated its belief that as partial stakeholder it can exert a stronger influence on the focus and cost efficiency of these investments. Furthermore, Lufthansa's equity stake gives evidence of a credible commitment to further investments in its network development at Frankfurt airport.

\subsection{Hub terminal expansion}

We proceed to the second scenario, in which both airport and HSC are faced with a hub terminal expansion and need to decide on the mode of vertical governance.

From the airport's perspective, price regulation does not serve as an adequate safeguard for quasi-rents created through a spot investment. Sunk costs in specialized terminal infrastructure and dedicated capacity render hub airports most vulnerable to holdup when the additional capacity is put into operation ( $t_{1}$ in Figure 2$)$. The HSC's threat of withholding growth is particularly credible in the early phase of infrastructure expansion projects. As time proceeds and expected demand materializes in the operating stage, the infrastructure company will gradually recoup its sunk cost by charging the airlines for the usage of infrastructure. As displayed in Figure 2, the airport's decrease in quasi-rents runs in the opposite direction to the HSC's accumulation of quasi-rents in its network development.

\footnotetext{
${ }^{26}$ Another stepping stone towards a more tightly coordinated relationship with its infrastructure suppliers is Lufthansa's plan to place a bid for the Deutsche Flugsicherung GmbH (German Air Traffic Control), which is going to be privatized in 2006 (Lufthansa, 2006).

${ }^{27}$ Cost-plus regulation, in a narrow sense, does not exist in Germany. Under German law (§ 43-1 LuftVZO and §6 LuftVG), the regulatory agencies at the federal state level are bound to approve the airport's charges proposal. The criteria usually applied are cost-relatedness, sustainability of infrastructure supply, and equitable discretion. The regulatory agencies, which are departments within one of the ministries at the federal state level, are thus not "true” economic regulators. In some instances, airlines and airports have negotiated contracts, attempting to assimilate a fee-cap contract. Once airport and airline have agreed on a fee cap formula, the airport will sign a contract under public law with the regulatory agency (for a comparison on regulatory institutions in Europe, see Wolf, 2003). Frankfurt airport, for example, has been governed by such a five-year “quasi” fee cap contract since 2002 (for a detailed analysis, see Klenk, 2004).
} 


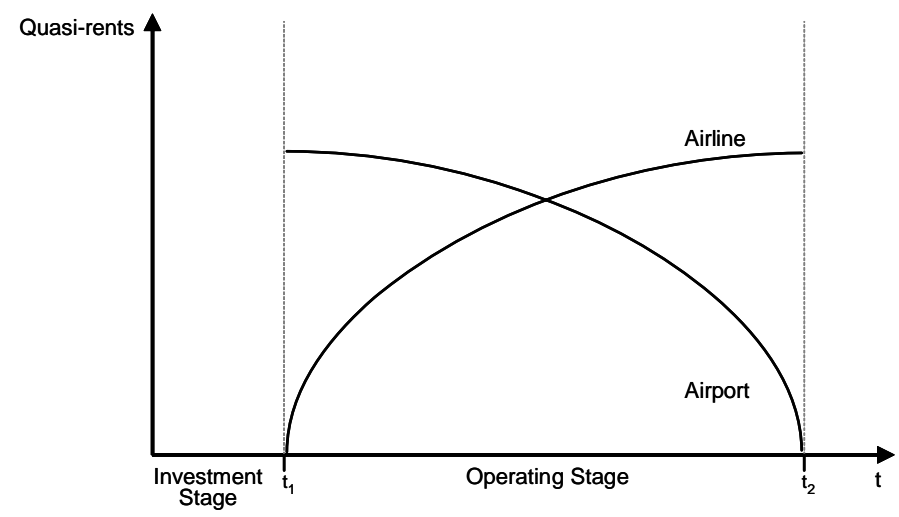

Figure 2: Development of quasi-rents in operating stage

Hub airports, anticipating this hold-up situation, require a credible commitment by the hub airline prior to the specific investment. Such a credible commitment can take the form of a financial or investment hostage. ${ }^{28}$ If such a credible commitment is not given, the hub airport might refrain from investing in a specialized terminal asset in the first place.

Proposition 2a: Hub airports need a credible commitment by the HSC in order to pursue a hub terminal infrastructure expansion project.

The hub airport's requirement for a jointly crafted investment hostage decreases if the specific infrastructure investment is undertaken for an established hub carrier. In the extreme, the new investment takes place at $t_{2}$ in Figure 2, when the airport has recouped its specific investment over the lifetime of the infrastructure. In this case, the HSC's extant quasi-rents, generated through its continuous complementary investments in its network development, serve as a sufficient credible commitment.

Proposition 2b: Extant quasi-rents of the HSC serve as a credible commitment in a hub terminal expansion and mitigate the airport's incentive to craft a joint investment hostage.

In both cases, a HSC with either an established or a non-established hub-and-spoke network will anticipate the accumulation of quasi-rents during the upcoming operating stage (commencing at $t_{2} / t_{1}$ ) of the infrastructure. Thus propositions $1 \mathrm{a}$ and $1 \mathrm{~b}$ hold equally in a hub terminal expansion project.

\section{Case study 2: Hub terminal expansion at Munich Airport}

Terminal 2 at Munich Airport was built and operated by multiple joint venture companies of Lufthansa (40\% ownership) and Munich Airport (60\% ownership). With the

\footnotetext{
${ }^{28}$ In his seminal work, Williamson (Williamson, 1983) discusses the role of hostages to support exchange in vertical supply relationships. Requirements for hostages, for example, equity ownership, may have ex-ante screening effects or ex-post bonding effects. For the hub airport, the latter in particular is significant.
} 
inauguration of Terminal 2 in 2003, the airport doubled its terminal capacity to 50 million passengers. The overall investment volume for the new terminal amounted to approximately 1.6 billion euros, with 1.2 billion euros accruing to the joint venture activities, hence a respective Lufthansa stake of 480 million euros. Despite Lufthansa's equity involvement, Munich Airport remains the formal owner and operator for all airport infrastructure facilities. The BOT project ${ }^{29}$ has not been accompanied by regulatory or institutional changes. Fees at Munich Airport are subject to the cost-plus regulation usual in Germany, with the Ministry of Commerce, Infrastructure, Transport and Technology of the federal state of Bavaria as responsible regulators.

One wonders what might have been the contributing factors for both partners to set up such a unique governance structure. In the mid 90's, Lufthansa was confronted with two, initially separate developments: first, Munich Airport intended to build a new terminal, as Terminal 1 was reaching its capacity limit, and second, growth at Lufthansa's primary hub airport Frankfurt was limited due to a lack of runway capacity. Lufthansa's strategic decision to follow a dual hub strategy and its need for terminal expansion at Munich Airport coincided, and resulted in the partnership. Lufthansa stated the following objectives for its equity involvement in the Terminal 2 expansion:

- Optimal terminal layout to support hub operations

- $\quad$ Branding Terminal 2 as a premium transferring facility for Lufthansa and Star Alliance customers

- A competitive airport fee level to develop a second hub-and-spoke network

Munich Airport, on the other hand, stated that its main objective for entering into a partnership with Lufthansa was to achieve a long-term commitment to develop Munich Airport as a second international hub airport in Germany (Klingenberg and Klingelhöfer, 2003). Furthermore, the airport claims that the Terminal 2 infrastructure expansion provided the basis for a significant regional welfare gain.

We have argued that the hub airport's quasi-rents reside in a spot investment and are rooted in physical asset specificity and dedicated asset specificity. The doubling of terminal capacity can not be explained by the local demand in the Munich catchment area, which is comparatively small. Due to the lock-in of other European HSC at their hub airport, Munich Airport depends on Lufthansa to channel transfer passengers via Munich by investing into new routes. Other relationship-specific investments, such as the highspeed automated baggage system, specialized boarding bridges, the three-story terminal layout, and a terminal satellite building, support the logistics and the transfer passenger and security-related processes of a hub operation. It is unlikely that in the absence of Lufthansa's $40 \%$ equity stake, the specific investments in Terminal 2 in terms of functionality and capacity would have taken place. The existing Terminal 1 infrastructure was initially designed to support point-to-point traffic. In 1997, when the decision was made to jointly invest in a hub terminal, Lufthansa was in the early phase of developing its hub-and-spoke network in Munich (Burghouwt and De Wit, 2005). We argue that in line with proposition 2a, Munich Airport safeguarded the transaction usage of infrastructure, by requiring Lufthansa to commit an equity stake. Lufthansa's $40 \%$ equity stake represents

\footnotetext{
${ }^{29}$ Terminal 2 represents a BOT project (Build, Own, Transfer), and thus falls back into public ownership at the end of the operating stage.
} 
an investment hostage, which, on the one hand, partially internalizes the relation-specific terminal investment and, on the other hand, binds Lufthansa to pursue the development of a second hub-and-spoke network at Munich Airport.

We now turn to the analysis of the governance structures themselves and the influence of regulation regimes on the organization decision. The joint venture governance structure represents a strong form of hybrid coordination. In the investment stage of Terminal 2, two special-purpose companies (denoted as MOB and IMMO in Figure 3) and a parity-staffed project team enabled the formulation of the user requirements, quick assessment of costbenefit trade-offs and conflict resolution during the project. While the building company (FMBAU) executed and controlled orders with its subcontractors, IMMO and MOB held asset ownership and financing responsibility. A trilateral advisory council, consisting of public owners, senior airline management, and airport representatives, controlled and decided on issues in the investment stage. The resulting organizational set-up is displayed in Figure 3.

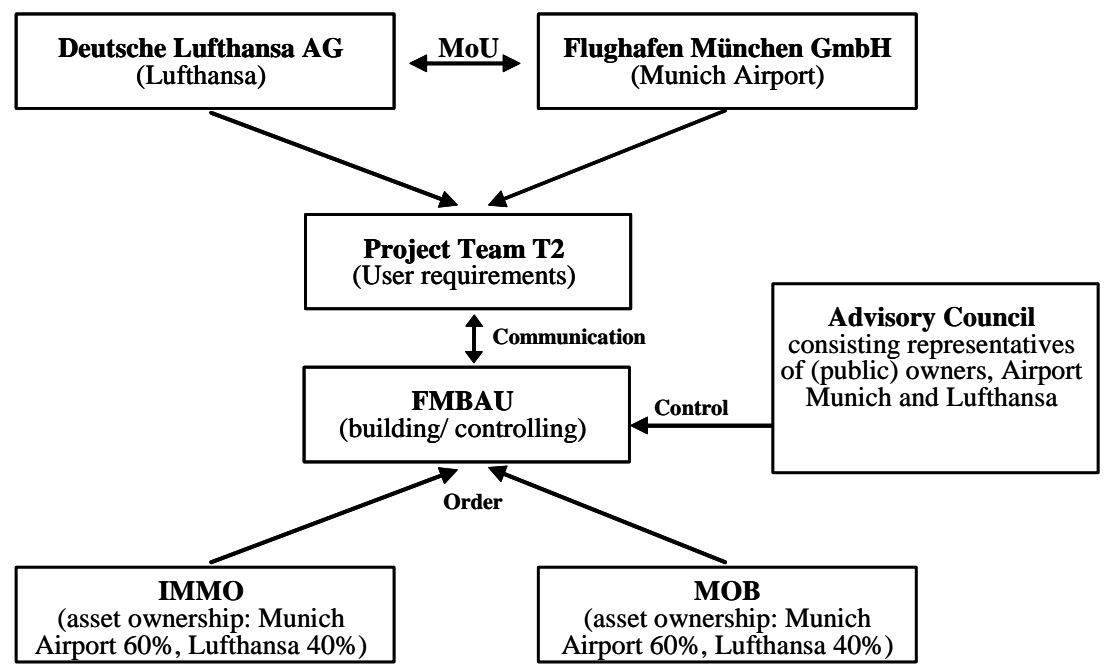

\section{Figure 3: Vertical governance structure in the investment stage}

Source: Klingenberg and Klingelhöfer, 2003, p.115

With the start of the operating stage, a separate joint venture company (T2- $\mathrm{BG}^{30}$ ) has taken over responsibility for running, maintaining, and developing Terminal 2. T2-BG is parity-staffed with employees from both partners and has autonomous responsibility for a sub-set of decisions related to operations, procurement of services, and marketing.

Prior to investing in the joint venture, both partners negotiated a Memorandum of Understanding (denoted as MoU in figure 3), which outlines the spirit and the instruments of cooperation. In line with recent literature on the economics of hybrid governance (Ménard, 2004), one encounters the pooling of resources (capabilities of both, airport and hub airline, are accessed in both investment and operating stage), contracting (within the

\footnotetext{
${ }^{30}$ The abbreviation T2-BG stands for Terminal 2 Betriebsgesellschaft, the name of the operating company of the Terminal 2.
} 
joint venture a multitude of procurement contracts, for example, for ground handling services, exist) and competition (Terminal 2 and Terminal 1 compete for other airline customers).

Munich Airport charges the airlines each time the transaction usage of infrastructure occurs. ${ }^{31}$ The cost base for the transaction usage of infrastructure includes depreciation, interest, running expenditures, and smaller investments for the development of both terminals. Conflicts on rent distribution will arise between carrier and airport, given that the pricing for the transaction usage of infrastructure needs to be adjusted continuously. Agreements need to be reached over such issues as the time span for cost recovery and the effects of deviations from forecasted traffic development. The joint determination of relevant cost information in the investment stage alleviates the problem of information asymmetry regarding re-financing needs during the operating stage. The information on the remaining cost positions and on the demand conditions can be evaluated mutually. Bilateral conflict-resolution mechanisms between the partners assure an equitable rent distribution.

The need for a privately crafted governance structures appears to be of particular importance here, as Lufthansa could not depend on regulation to serve as a sufficient safeguard against opportunistic pricing. The superior information-sharing and conflictresolution mechanisms in the organizational set-up described corroborate propositions $1 \mathrm{a}$ and $1 b$.

\subsection{Low cost terminal expansion at base airport}

In their negotiations on the establishment of new bases in their network, value-based carriers face a large number bargaining situation with prospective airports ex-ante. However, once the VBA stations aircrafts and crews, invests in regional and route-specific brand-building, and in some rare cases, establishes an aircraft maintenance facility at its base airport, a fundamental transformation occurs. An ex-post change of its base airport or a downgrade to a non-base airport will result in a financial loss. A farsighted VBA, anticipating its increasing dependency on its base airports, will thus seek to protect these evolving quasi-rents in the development of its base airport.

Prospective base airports, on the other hand, may or may not be faced with an investment in dedicated terminal capacity to accommodate the future growth of the VBA. Provided that idle capacity is not available, we argue that base airports will invest into dedicated terminal capacity. ${ }^{32}$

Therefore, it is efficient for both partners to enter into a long-term agreement. The rationale of these contracts is the VBA's desire to fix prices in the long run, while the respective base airport attempts to assure a certain traffic development. Therefore, one would expect prices for the transaction usage of infrastructure to be fixed to a forecasted traffic development. Given that the base airport is vulnerable in the early phase of the network development, a unilateral commitment in the form of take-or-pay provisions or

\footnotetext{
${ }^{31}$ The charges applicable to the usage of terminal infrastructure in Germany, include the passenger service charges and central infrastructure charges (for the usage of essential facilities for ground handling operations).

${ }^{32}$ Even though investment volumes in these general-purpose, low-cost facilities are low compared to hub terminal investments and to a certain extent marketable to alternative LCCs, we argue that airports seek some form of ex-ante protection for their quasi-rents.
} 
investment hostages may be required. Such safeguards support continuity in the bilateral relationship.

Proposition 3a: VBAs seek to establish long-term contractual safeguards with their base airports to protect against the expropriation of their quasi-rents.

Proposition 3b: Base airports seek to establish complementary safeguards to protect their investment in carrier-specific infrastructure capacity.

The relationships between VBAs and these airports are in many cases not explicitly administered by a regulator. However, VBAs and base airports are still faced with difficulties in their desire to enter into exclusive bilateral contracts, as airport charges are bound to be transparent, cost-related, and non-discriminatory. ${ }^{33}$ The legal regulations and guidelines affecting their contractual relationships have become increasingly complex. At the supranational level, the European Commission has recently specified in its State Aid Guidelines the circumstances in which a publicly owned airport can enter into marketing agreements. Any marketing agreement must be publicly announced, available to all interested carriers, temporally limited, and must pursue profit objectives. On the other hand, challenges might also be brought forward against discriminatory pricing, based on competition law at the European as well as at the national level. Examples of recent legal challenges include the Charleroi/Ryanair decision by the European Commission.

Faced with these contracting constraints in their institutional environment, VBAs and base airports will hesitate to bring any contractual disputes to court. To a certain extent, they can expect reputation to serve as an informal safeguard that keeps the contract in a self-enforcing range. As quasi-rents and uncertainty become significant, however, complementary formal safeguards might be crafted as well to support the continuity of exchange. $^{34}$

Proposition 3c: Base airports and VBAs seek complementary formal and informal safeguards, as they are uncertain about the enforceability of their exclusive bilateral longterm agreements.

\section{Case Study 3: Contracting practices between VBAs and their base airports}

To substantiate these propositions, we investigate the contracting practices between VBAs and base airports in Germany and neighbouring countries. As the contractual relations described are confidential and sometimes informal, detailed information on the spirit and terms of these agreements are generally not available to outside parties. The following case study is based on information gathered from a series of informal expert interviews and the limited publicly available information. ${ }^{35}$ The contractual relations analyzed include both ongoing as well as prospective supply relationships between the base airports and VBAs.

\footnotetext{
${ }^{33}$ The International Civil Airline Organization (ICAO) recommends these three core principles in determining airport charges. These principles are, however, not legally binding.

${ }^{34}$ Pioneering work in contracting under regulatory constraints has been undertaken by Palay (Palay, 1985). In his analysis on the supply relationship between shippers and railroad carriers, it was shown that parties avoid regulatory constraints by crafting informal agreements to safeguard their idiosyncratic investments.

${ }^{35}$ We conducted expert interviews with senior management at these base airports, senior procurement managers for airport services at VBAs and HSCs, as well as with other industry experts.
} 
We have included these prospective exchange settings, when negotiations have already taken place, but contract execution hinges on blocked infrastructure expansion projects. Table 2 displays the investigated base airport/VBA supply relationships in Germany, and shows the investment volume along with the size of the terminal capacity expansion. Although some of these airports have expanded terminal capacity, we have only included terminal projects that qualified as a terminal expansions dedicated to a single VBA. Regional airports are defined as airports with a passenger volume of less than 1 million passengers per annum prior to the VBA's expansion.

\begin{tabular}{|l|c|l|l|l|}
\hline Airport & VBA & $\begin{array}{c}\text { Regional } \\
\text { airport }\end{array}$ & $\begin{array}{c}\text { Terminal Capacity } \\
\text { Expansion } \\
\text { (Passenger p.a) }\end{array}$ & $\begin{array}{c}\text { Investment } \\
\text { Volume }\end{array}$ \\
\hline Berlin (SXF) & $\begin{array}{c}\text { Germanwings/ } \\
\text { Easyjet }\end{array}$ & No & 2.5 mill. & 12.5 mill. $€$ \\
\hline Bremen (BRE) & Ryanair & No & 1.0 mill & 10.0 mill. $€$ \\
\hline Hahn (HHN) & Ryanair & Yes & 4.5 mill. & 25 mill. $€$ \\
\hline Lübeck (LBC) & Ryanair & Yes & N/A & N/A \\
\hline Stuttgart (STR) & Germanwings & No & None & None \\
\hline Hamburg (HAM) & Germanwings & No & None & None \\
\hline Köln (CGN) & Germanwings & No & None & None \\
\hline Dortmund (DTM) & Easyjet & Yes & None & None \\
\hline Neuhardenberg & Ryanair & Yes & 1.0 mill. & 5.0 mill. $€$ \\
\hline
\end{tabular}

Table 2: VBA - Base airport supply relationships in Germany

In the supply relationships analyzed here between VBAs and base airports, three types of contractual agreements have been identified: (i) Long-term bilateral agreements (ii) marketing agreements / structural changes in airport charges, and (iii) investment hostages.

In long-term bilateral agreements, VBAs and base airports set the number of airplanes stationed and passenger development. These contracts are of an either informal or formal nature.

"Our new 10 year deal with Brussels Charleroi Airport commits Ryanair to invest \$240M in new aircraft and deliver 2.3M passengers p.a.” (Michael O’Leary, CEO Ryanair, Ryanair press release, 14 December 2005)

Embedded in these bilateral agreements, we find contractual types (ii) and (iii).

After a bilateral agreement has been reached to establish a new base airport, the airport will either heavily revise its airport charges and/or issue a tailor-made marketing program. These type (ii) agreements attempt to achieve two objectives: first, to provide a contractual safeguard to the base carrier for the fixation of prices in the long run, and second, to avoid legal disputes. ${ }^{36}$ In the cases observed, the new charges resulted in a significant pricing decrease in comparison to the prior airport charge structures. Through volume clauses and other special provisions, base airports attempt to tailor the agreement to base carriers.

In some cases, we observed that VBAs were required to provide complementary formal safeguards in the form of investment hostages or financial hostages (type iii). Such hostages in the form of "take-or-pay clauses" and/or (partial) provision of capital to finance terminal investments serve as credible commitments to support specific

\footnotetext{
${ }^{36}$ In the past, these marketing agreements were usually not made public. However, this is changing in response to the latest court rulings and guidelines at the European level.
} 
investments in terminal capacity. In conjunction with the new infrastructure expansion at its base airport in Frankfurt-Hahn, Ryanair stated the following:

"Ryanair has committed itself to invest one billion euros in the form of stationed aircraft at Hahn
Airport. ... with over 50 routes and eight million passengers per annum, Ryanair will turn Hahn
airport into one of the largest and fastest growing airports in Germany. Furthermore, Ryanair will
provide 12.5 million euros or $\mathbf{5 0 \%}$ of the capital to the investment in the new passenger
terminal. And on top of this, Ryanair will invest in an aircraft maintenance facility at Hahn
airport." (Michael O'Leary, CEO Ryanair, Ryanair press release, 11 November 2005, emphasis
added, own translation)

Another indication can be inferred from a statement by Infratil, a private airport operator that recently bought a $90 \%$ equity stake in Lübeck airport and intends to develop the airport as the Ryanair base airport for northern Germany.

"Due to the adverse court ruling and [Lübeck] airport's resulting inability to extend the runway as planned, this agreement, in which Ryanair had agreed to guarantee a minimum number of passengers each year, starting at 1 million departing passengers in the year to October 2006, rising to 2.8 million departing passengers in year 10, has now lapsed“ (www.infratil.com, emphasis added)

Parallel to its attempt to establish a new base airport in Lübeck, Ryanair has entered into a long-term agreement with publicly-owned Bremen Airport. Winning the airport's recent European tender, Ryanair commits itself to deliver approximately one million passengers per annum. An essential part of the agreement is a long-term lease of an existing warehouse facility, which will be refurbished into an exclusive Ryanair terminal. Using this dedicated facility, allows Ryanair to avoid paying the passenger service and the central infrastructure fees for the existing terminal-related assets at Bremen Airport.

Our expert interviews provided further evidence that small regional airports, in particular, seek a volume guarantee through a take-or-pay clause or through a financial or investment hostage. In cases in which idle terminal capacity was marketed, such complementary formal safeguards could not be found.

As base airports become well established in their networks, it can be expected that VBAs will seek even stronger safeguards. At its home base Dublin, for example, Ryanair entered a detailed proposal to fund and construct a terminal with a passenger capacity of ten million in response to the Irish government's call for investors in an independent second terminal at Dublin airport. ${ }^{37}$ Although the Irish Government decided against a competing second terminal, we regard Ryanair's proposal for a specialized vertical governance structure as a response guarding its quasi-rents arising from sunk investments in brand capital and site-specific investments.

\section{Discussion}

We have set out to explore vertical governance between airlines and airports with transaction cost theory as our analytical framework. Airport privatization and infrastructure expansion projects lead airlines and airports to re-evaluate their "firm boundaries" in the context of the liberalized European air transport market.

On the basis of five stylized airline/airport supply relationships in linear and hub-andspoke networks, we have argued that in each of these relationships, differences in the attributes of the transaction usage of infrastructure result in different contracting problems.

\footnotetext{
${ }^{37}$ See McLay and Aisling (2005) for an overview on the issues involved of a second competing terminal at Dublin Airport.
} 
The supply relationship HSC and hub airport in particular is characterized by high mutual dependency, high frequency, substantial uncertainty, and a high cost of performance evaluation. The HSC's quasi-rents are rooted in site-specific assets (slots, traffic rights, and maintenance facilities) and specificity of human capital assets in the scheduling process. While most of the airline's quasi-rents are built up continuously over the development of its hub-and-spoke schedule, quasi-rents at the hub airport are created through spot investments. New capacities in hub terminals are to a great extent specific in size and functionality to accommodate future growth in transfer passengers and to enable hubbing processes.

In contrast to the typical dyadic interfirm relationship analyzed in the TCE literature, the transaction usage of infrastructure is usually administered by a government regulator or governed by a (partial) public owner. We proposed that regulators with a high reputation mitigate the HSC's incentive to craft a parallel private governance structure. However, if the HSC does not expect the regulator to protect its quasi-rents sufficiently, it will seek (partial) equity ownership of its hub airport to access bilateral conflict resolution and enforcement mechanisms.

Prices administered by a regulator, however, do not safeguard the hub airport's quasirents arising from a specific spot investment. We argue that an investment in hub terminal infrastructure exposes the airport to potential hold-ups of the hub carrier. In particular, HSCs, which have yet to invest in the development of their hub-and-spoke schedule, can mount a credible threat to expropriate these quasi-rents by withholding volume growth in hub development. We suggest that hub airports require a credible commitment by the hub airline prior to investing in a specific hub infrastructure.

For the supply relationship between VBAs and base airports, we have argued that the base airport's dependency on a particular VBA arises from a spot investment in dedicated terminal capacity. The VBA's business model, on the other hand, requires significant investments in the development of a low-cost brand in the catchment area as well as at the route level. We have hypothesized that both parties will seek long-term agreements to safeguard both projected volume growth and prices for the transaction usage of infrastructure. We have argued - and presented initial evidence - that these contracts are supported by complementary safeguards (changes in airport fee structures, designated marketing programs). Smaller regional airports will furthermore require additional guarantees in the form of take-or-pay clauses or hostages prior to their investment decision.

Three case studies have been presented to support our proposition as well as to reveal further opportunities for a more in-depth exploration of the complexities in the governance decision.

First, airlines appear to be particularly concerned about the efficient provision of infrastructure in terms of cost as well as functionality in the investment stage. Transactions in the investment phase need to be analyzed at a more detailed level. Complementary theories, such as capability-based theory and organization theory, should be applied to reveal how different vertical governance structures facilitate the generation of innovation, that is, by building specific assets, in the first place.

Second, the governance modes of regulation and (partial) public ownership need a more in-depth analysis. In contrast to the structural perspective of TCE, we have argued in this paper that privately crafted governance structures can act as a complement to regulation. However, we need to develop a more thorough understanding of how different 
forms of regulation, in combination with public ownership and different institutional environments influence governance decisions between airlines and airports.

Third, if our propositions hold, economic policy should design rules that allow for new vertical governance structures while keeping the potential for discriminatory practices to a minimum. Regulation has been shown to entail difficulties in dealing with hybrid organizational structures, as presented in our case studies (Ménard, 1998). Given our findings, we argue that these new organizational solutions enhance welfare and are not designed to soften competition. However, the "rules of the game" may still need to be modified. Research on the interdependencies between the institutional environment and the level of governance will certainly inform any policy decision.

Finally, the evidence presented here needs to be supplemented by more in-depth studies. Upcoming privatization of airports and air traffic control, as well as new terminal expansion projects in the coming years, will provide further empirical evidence. In our view, detailed studies analyzing these specialized governance structures at the microanalytical level will be especially informative. Furthermore, comparative studies on the differences in vertical governance between airports and airlines in the different European countries and the United States will generate further evidence on the influence of the institutional environment. Our paper presents a first institutional explanation for recently observed changes in vertical governance between airlines and their infrastructure suppliers, but further work along related lines of research is much needed.

\section{$5 \quad$ References}

Aghion, P. and P. Bolton (1987) "Contracts as a Barrier to Entry," American Economic Review, 77: 385-395.

Albers, S., B. Koch and C. Ruff (2005) "Strategic Alliances between Airlines and Airports-A Theoretical Assessment and Practical Evidence,” Journal of Air Transport Management, 11: 49-58.

Anonymous (1990) “The Antitrust Implications of Airport Lease Restrictions," Harvard Law Review, 104: 548-568.

Barney, J. (1991) "Firm Resources and Sustained Competitive Advantage," Journal of Management, 17: 99-120.

Barrett, S. (2004) "How Do the Demands for Airport Services Differ between Full Service and Low Cost Carriers?” Journal of Air Transport Management, 10: 33-39.

Boerner, C. and T. Macher (2002) "Transaction Cost Economics: An Assessment of Empirical Research in the Social Sciences,” unpublished. http://faculty.msb.edu/jtm4/Papers/JLEO.pdf

Brenck, A., C. Hirschhausen, M. Holzhey, L. Hübner, B. Peter, T. Schulin, S. Schultz and J. Siegmann (2004) "SYNETRA - Synergien zwischen Bahnnetz und - transport: Praxis, Probleme, Potentiale,” Gutachten im Auftrag des Bundesministeriums für Bildung und Forschung. 
Brueckner, J. and P. Spiller (1994) "Economies of Traffic Density in the Deregulated Airline Industry,” Journal of Law and Economics, 37(2): 379-415.

Burghouwt, G. and J. De Wit (2005) "Temporal Configurations of European Airline Networks,” Journal of Air Transport Management, 11: 185-198.

Caves, D., L. Christensen and M. Tretheway (1984) "Economies of Density versus Economies of Scale: Why Trunk and Local Service Airline Cost Differ," Rand Journal of Economics, 15: 471-489.

Crocker, K. and S. Masten (1996) "Regulation and Administered Contracts Revisited: Lessons from Transaction-Cost Economics for Public Utilities Regulation,” Journal of Regulatory Economics, 9: 5-39.

Dresner, M., R. Windle and Y. Yao (2002) "Airport Barriers to Entry in the US," Journal of Transport Economics and Policy, 36(2): 389-405.

Fuhr, J. (2006) “Governance of Services - Empirical Evidence on Ground Handling Contracts in Air Transport," unpublished working paper.

Ghosh, M. and G. John (1999) "Governance Value Analysis and Marketing Strategy," Journal of Marketing, 63: 131-145.

Goldberg, V. (1976) "Regulation and Administered Contracts,” Bell Journal of Economics, 7(2): 426-452.

Grossmann, S. and O. Hart (1986) "The Cost and Benefits of Ownership: A Theory of Vertical and Lateral Integration,” Journal of Political Economy, 94: 691-719.

Hart, O. and J. Moore (1990) "Property Rights and the Nature of the Firm," Journal of Political Economy, 98: 1119-1158.

Hirschhausen, C., T. Beckers, A. I. Czerny and S. Müller (2004) "Privatisation and Regulation of German Airports," Studie von DB Research und des FG Wirtschafts- und Infrastrukturpolitik (WIP) der TU Berlin.

Holmstrom, B. and J. Roberts (1998) “The Boundaries of the Firm Revisited,” Journal of Economic Perspectives, 12: 73-94.

Jacobides, M. and S. Winter (2005) "The Co-evolution of Capabilities and Transaction Costs: Explaining the Institutional Structure of Production,” Strategic Management Journal, 26: 395-413.

Joskow, P. (2005) "Vertical Integration,” in C. Ménard and M. M. Shirley (ed.), Handbook of New Institutional Economics, Springer, Dodrecht: 319-348.

Klein, B., R. A. Crawford and A. A. Alchian (1978) "Vertical Integration, Appropriable Rents, and the Competitive Contracting Process," Journal of Law and Economics, 21: 297326. 
Klein, P. (2005) “The Make-or-Buy Decision: Lessons from Empirical Studies,” in C. Ménard and M. M. Shirley (ed.), Handbook of New Institutional Economics, Springer, Dodrecht: 435-464.

Klenk, M. (2004) "New Approaches in Airline/Airport Relations: The Charges Framework of Frankfurt Airport," in P. Forsyth, D. Gillen, A. Knorr, O. Mayer, H.-M. Niemeier and D. Starkie (ed.), The Economic Regulation of Airports: Recent Developments in Australasia, North America and Europe, Ashgate, Aldershot: 125-140.

Klingenberg, C. and S. Klingelhöfer (2003) "Private Infrastructure Financing: The Case of Terminal 2 at Munich Airport,” in C. Hirschhausen, T. Beckers and K. Mitusch (ed.), Trends in Infrastructure Regulation and Financing - International Experience and Case Studies from Germany, Edward Elgar: Cheltenham.

Langner, S. (1995) "Contractual Aspects of transacting in slots in the United States," Journal of Air Transport Management, 2: 151-161.

Lufthansa (2006) Annual Report (Manuskriptfassung). http://www.lufthansafinancials.de/lhir/pdf/de/pk_manuskriptfassung_d.pdf

Masten, S. (1984) "The Organization of Production: Evidence from the Aerospace Industry,” Journal of Law and Economics, 26: 403-417.

Masten, S., J. Meehan and E. Snyder (1991) “The Costs of Organization,” Journal of Law, Economics and Organization, 7: 1-25.

Masten, S. and S. Saussier (2002) "Econometrics of Contracts: An Assessment of Empirical Literature in Contracting,” in E. Brousseau and J.-M. Glachant (ed.), Economics of Contracts, Cambridge University Press, Cambridge: 273-292.

McLay, P. and R. Aisling (2005) "Competition between Airport Terminals: The Issues Facing Dublin Airport,” Geary Discussion Paper Series.

Ménard, C. (1998) "Maladaptation of Regulation to Hybrid Organizational Forms," International Review of Law and Economics, 18: 403.

Ménard, C. (2004) “The Economics of Hybrid Organizations,” Journal of Institutional and Theoretical Economics, 160: 345-376.

Ordover, J., G. Saloner and S. Salop (1990) “Equilibrium Vertical Foreclosure,” American Economic Review, 80(1): 127-142.

Palay, T. (1985) "The Avoidance of Regulatory Constraints: The Use of Informal Contracts,” Journal of Law, Economics and Organization, 1: 155-175.

Panzar, J. (1989) “Technological Determinants of Firm and Industry Structure,” in R. Schmalensee and R. D. Willig (ed.), Handbook of Industrial Organization, North-Holland, Amsterdam, 4-56. 
Peteraf, M. (1993) "The Cornerstones of Competitive Advantage: A Resource-based View,” Strategic Management Journal, 14: 179.

Pirrong, C. (1993) "Contracting Practices in the Bulk Shipping Market: A Transactions Cost Explanation,” in S. Masten (Ed.), Case Studies in Contracting and Organization, Oxford University Press, New York: 130-162.

Reynolds-Feighan, A. (2001) "Traffic Distribution in Low-cost and Full-service Carrier Networks in the US Air Transportation Market,” Journal of Air Transport Management, 7: 265-275.

Rindfleisch, A. and J. Heide (1997) "Transaction Cost Analysis: Past, Present, and Future Applications,” Journal of Marketing, 61: 30-54.

Schulte, S. (2005) Capex Program Frankfurt: Lift to the Future. http://www.fraport.de/cms/investor_relations/dokbin/67/67831.investor_day_2005_present ation_dr_schult@de.pdf

Serebrisky, T. (2003) “Market Power: Airports,” Public Policy for the Private Sector, Note Number 259(March). http://rru.worldbank.org/PapersLinks/Open.aspx?id=2002

Shy, O. (2001) The Economics of Network Industries. Cambridge University Press: London.

Starkie, D. (2002) “Airport Regulation and Competition," Journal of Air Transport Management, 8: 63-72.

Teece, D., G. Pisano and A. Shuen (1997) "Dynamic Capabilities and Strategic Management,” Strategic Management Journal, 18-42: 509-533.

Tirole, J. (1988) The Theory of Industrial Organization. MIT Press: Cambridge.

Wernerfelt, B. (1984) “A Resource-Based View of the Firm,” Strategic Management Journal, 5: 171-180.

Williamson, O. (1971) "The Vertical Structure of Production: Market Failure Considerations,” American Economic Review, 61: 112-123.

Williamson, O. (1983) “Credible Commitments: Using Hostages to Support Exchange," American Economic Review, 73: 519-540.

Williamson, O. (1985) The Economic Institutions of Capitalism. The Free Press: New York.

Williamson, O. (1991) "Comparative Economic Organization: The Analysis of Discrete Structural Alternatives,” Administrative Science Quarterly, 36: 269-296.

Williamson, O. (1996) The Mechanisms of Governance. Oxford University Press: Oxford. 
Williamson, O. (1999) "Public and Private Bureaucracies: A Transaction Cost Economics Perspective,” Journal of Law, Economics and Organization, 15: 306-342.

Williamson, O. (2005) “The Economics of Governance,” American Economic Review, 95: $1-18$.

Wolf, H. (2003) Privatisierung im Flughafensektor - eine ordnungspolitische Analyse, Springer: Heidelberg.

Wolf, H. (2004) “Airport Privatisation and Regulation: Getting the Institutions Right,” in P. Forsyth, D. Gillen, A. Knorr, O. Mayer, H.-M. Niemeier and D. Starkie (ed.), The Economic Regulation of Airports: Recent Developments in Australasia, North America and Europe, Ashgate, Aldershot: 201-212. 